\title{
Construction of a Reduction-responsive DNA Microsphere using a Reduction- cleavable Spacer based on a Nitrobenzene Scaffold
}

\author{
Sayuri L. Higashi, ${ }^{1}$ Ayaka Isogami, ${ }^{2}$ Junko Takahashi, ${ }^{2}$ Aya Shibata,${ }^{2}$ \\ Koichiro M. Hirosawa, ${ }^{3}$ Kenichi G.N. Suzuki, ${ }^{3}$ Shunsuke Sawada, ${ }^{4}$ Shinya Tsukiji $, 4,5$ \\ Kazunori Matsuura, ${ }^{6,7}$ Masato Ikeda ${ }^{1,2,3,8 *}$
'United Graduate School of Drug Discovery and Medical Information Sciences, Gifu University, 1-1 Yanagido, Gifu 501-1193, Japan ${ }^{2}$ Department of Chemistry and Biomolecular Science, Faculty of Engineering, Gifu University, 1-1 Yanagido, Gifu 501-1193, Japan
${ }^{3}$ Institute for Glyco-core Research (iGCORE), Gifu University, 1-1 Yanagido, Gifu 501-1193, Japan
${ }^{4}$ Department of Nanopharmaceutical Sciences, Nagoya Institute of Technology, Gokiso-cho, Showa-ku, Nagoya 466-8555, Japan
${ }^{5}$ Department of Life Science and Applied Chemistry, Nagoya Institute of Technology, Gokiso-cho, Showa-ku, Nagoya 466-8555, Japan
${ }^{6}$ Department of Chemistry and Biotechnology, Graduate School of Engineering, Tottori University, Tottori 680-8552, Japan
${ }^{7}$ Centre for Research on Green Sustainable Chemistry, Tottori University, Tottori 680-8552, Japan

${ }^{8}$ Institute of Nano-Life-Systems, Institutes of Innovation for Future Society, Nagoya University, Furo-cho, Chikusa-ku, Nagoya, 464-8603, Japan

E-mail:m_ikeda@gifu-u.ac.jp (MI)

Equal contribution (SLH, AI) These authors contributed equally

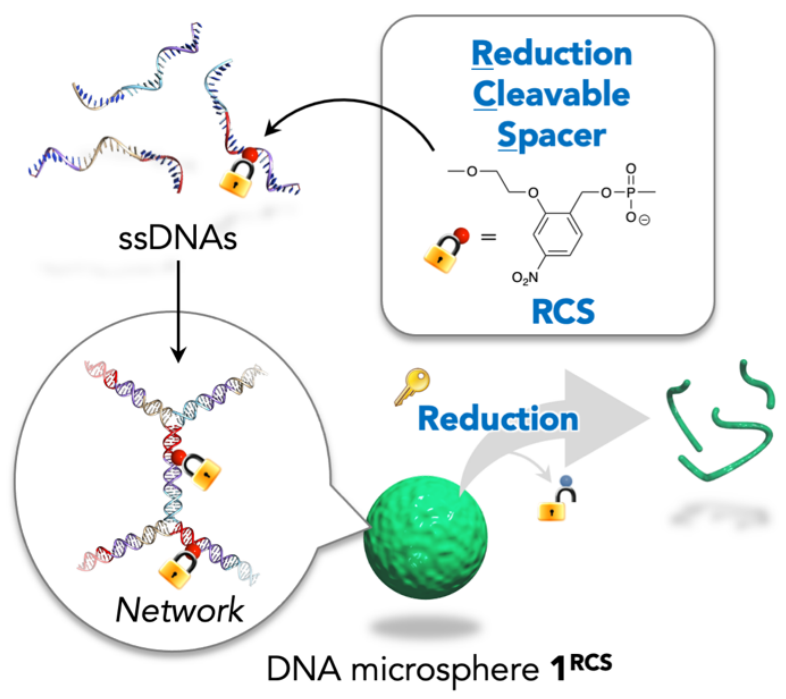

Table of Contents: We describe that the reduction-cleavable spacer (RCS) containing a nitrobenzene scaffold can be incorporated into a single-stranded DNA sequence to enable the construction of a reductionresponsive DNA architecture with spherical morphology at micrometer scale. The RCS could allow for the introduction of the reduction-responsiveness into various functional oligonucleotides as well as nucleic acidbased architectures. 


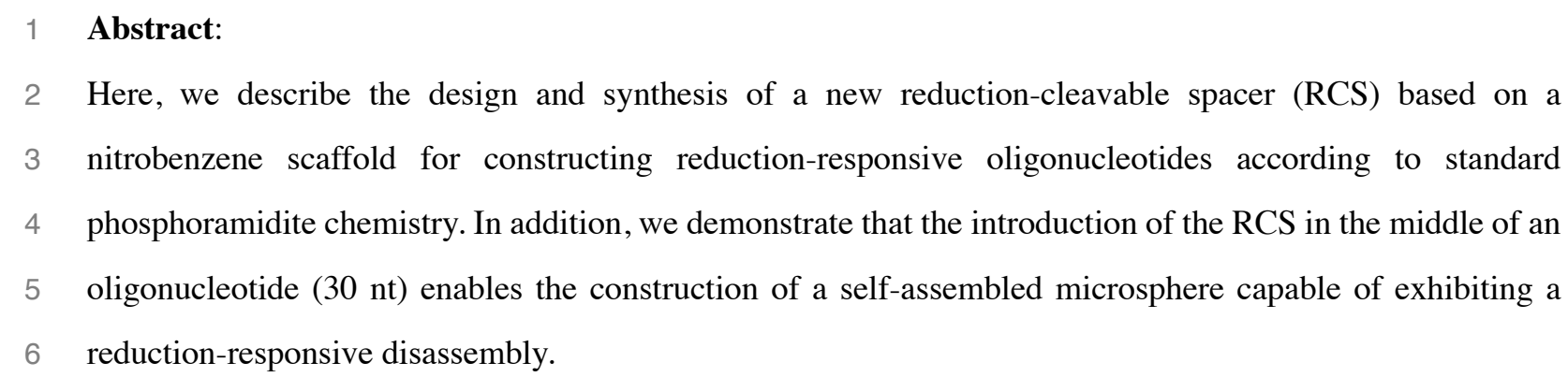

\section{Introduction}

Nucleic acids have been employed as programmable building blocks in the construction of various DNA nanostructures through self-assembly, which is based on Watson-Crick base pairing [1]. DNA nanostructures with stimuli-responsive properties have been used in various applications such as sensors [2], controlled release and delivery [3], and actuators [4]. For introducing stimuli responsiveness in constitutional nucleic acid strands, two distinct chemical approaches using cleavable bonds have been employed: These approaches are (i) the modification of nucleotide (monomer) units and (ii) the introduction of a stimuliresponsive cleavable spacer in the middle of a nucleic acid strand [5] (Figure 1). Our group has devoted research efforts to develop redox-responsive nucleic acids. For instance, we developed a reductionresponsive guanosine monomer unit that can be introduced into DNA aptamer [6] and DNAzyme [7] using the chemical approach (i). Recently, we have established a postmodification approach to introduce reduction [8] and oxidation [9]-responsive units (nitrobenzyl and boronobenzyl groups, respectively) into the terminal phosphate groups of nucleic acids. Nevertheless, to effectively trigger a dynamic structural change in a selfassembled structure of nucleic acids in response to redox-stimuli, the development of redox-responsive spacer units using the chemical approach (ii) is desired. Regarding this, photo-cleavable spacers have been successfully used to induce dynamic structural transitions in DNA nanostructures [10]. For example, the photo-controlled release of entrapped substances from DNA origami nanostructures [11] and DNA microcapsules [12] have been reported. In addition, enzyme-cleavable spacers based on a dipeptide have been developed to promote the applications of therapeutic oligonucleotides [13].

Here, we describe the design and synthesis of a new reduction-cleavable spacer (RCS; Figure 1B) based on a nitrobenzene scaffold for constructing reduction-responsive nucleic acids according to standard phosphoramidite chemistry. In addition, we demonstrate the introduction of the RCS in the middle of an oligonucleotide sequence (30 nt) for constructing self-assembled microspheres [14] exhibiting reductionresponsive disassembly. 

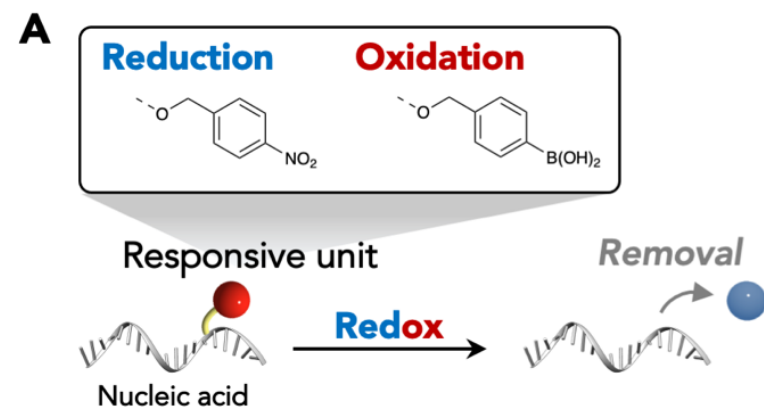

B

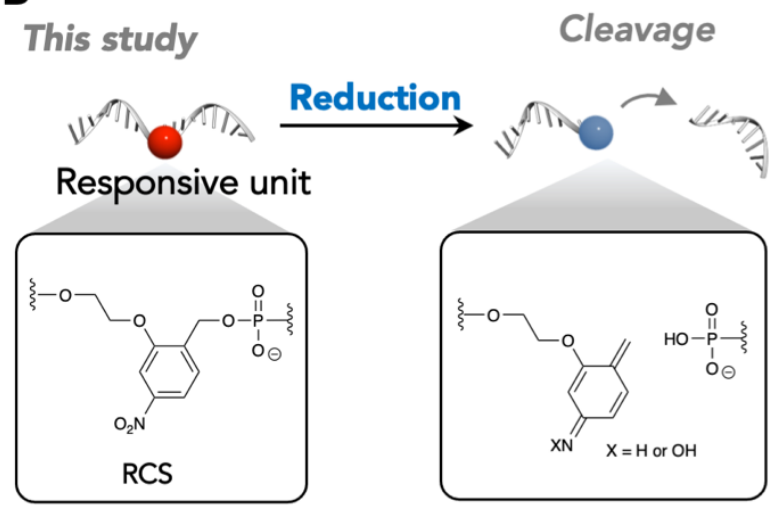

Figure 1 Redox-responsive nucleic acids based on the (A) modification of nucleotide (monomer) units with a cleavable chemical bond (typical reduction and oxidation responsive units, which can be introduced at nucleobase [5c, 5f, 6, 7] or phosphate [5c, 5g, 8, 9] moiety, are shown) and (B) introduction of a stimuliresponsive cleavable spacer in the middle of strand. The chemical structure of reduction-cleavable spacer (RCS) consisting of a nitrobenzene scaffold and plausible structure after cleavage are shown.

\section{Results and discussion}

The molecular design of the new RCS is depicted in Figures $\mathbf{1}$ and $\mathbf{2}$ and the synthetic scheme is shown in Figure S1 (Supporting Information). After the reduction of nitro groups in the RCS to amino and/or aminoxy groups [6a], a cleavage reaction via $\beta-1,6-$-elimination could occur, as depicted in Figure 1B. The p-nitrobenzene scaffold including RCS can show the nicotinamide-adenine dinucleotide (phosphate) (NA(P)DH)-dependent cleavage with the aid of enzymes, such as a nitroreductase [6a, 15, 16]. In contrast, no response toward thiol-reducing agents including reduced glutathione, which cannot reduce the nitro groups, is expected [8]. In this study, we introduced the RCS into a single-stranded DNA (ssDNA) s1 to obtain $\mathbf{s 1}^{\mathbf{R C S}}$ (Figure 2A). The resulting $\mathbf{s 1}^{\mathbf{R C S}}$ could form DNA microspheres by combining with two additional ssDNAs, i.e., s2 and s3, via thermal annealing process. The process is shown in Figure 2B [14]. In addition, because the RCS was introduced between the TWJ core and SE sequence, the reductionresponsive cleavage could result in the disassembly of DNA microspheres through the loss of their threedimensional network structure as depicted in Figure 2B. 
A TWJ core Sticky end (SE)

$\mathbf{s} 1: 5$ '-GGCGTGGTAGACCGCACTCGAAAAATTTTT-3 '

s2 : 5 ' -CGAGTGCGGTGACGATGCCTAAAAATTTTT-3'

s3 : 5 ' -AGGCATCGTCCTACCACGCCAAAAATTTTT-3 '

s1 ${ }^{\text {w/O SE }}: 5^{\prime}$-GGCGTGGTAGACCGCACTCG-3'

s1 $1^{\text {RCs }}: 5$ '-GGCGTGGTAGACCGCACTCG-0

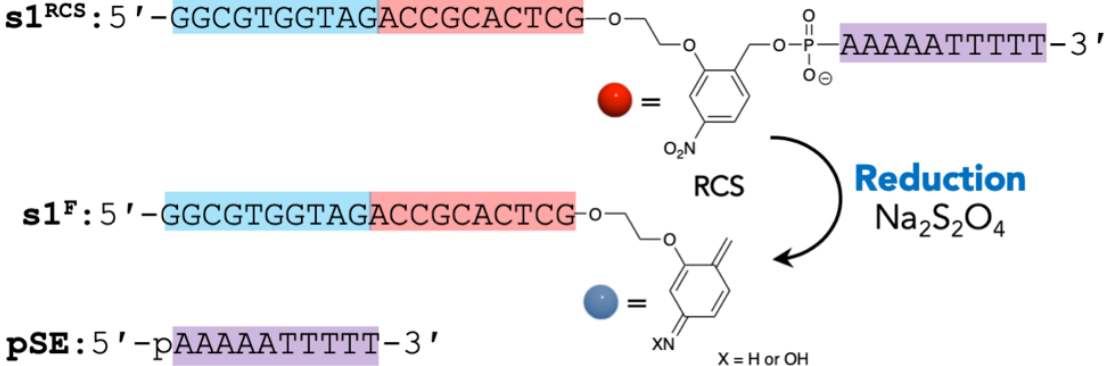

B

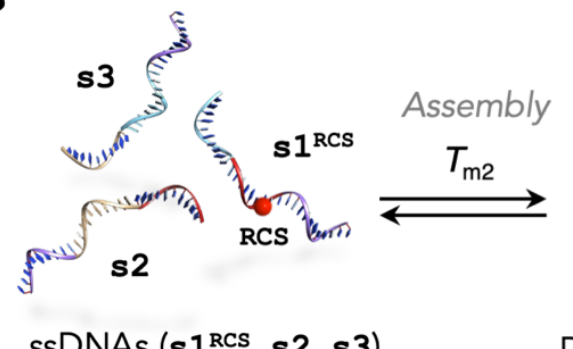

ssDNAs (s1 $\left.1^{\mathrm{RCs}}, \mathbf{s} 2, \mathrm{~s} 3\right)$

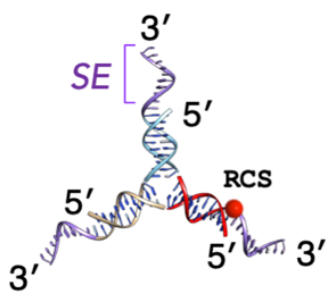

DNA three-way junction

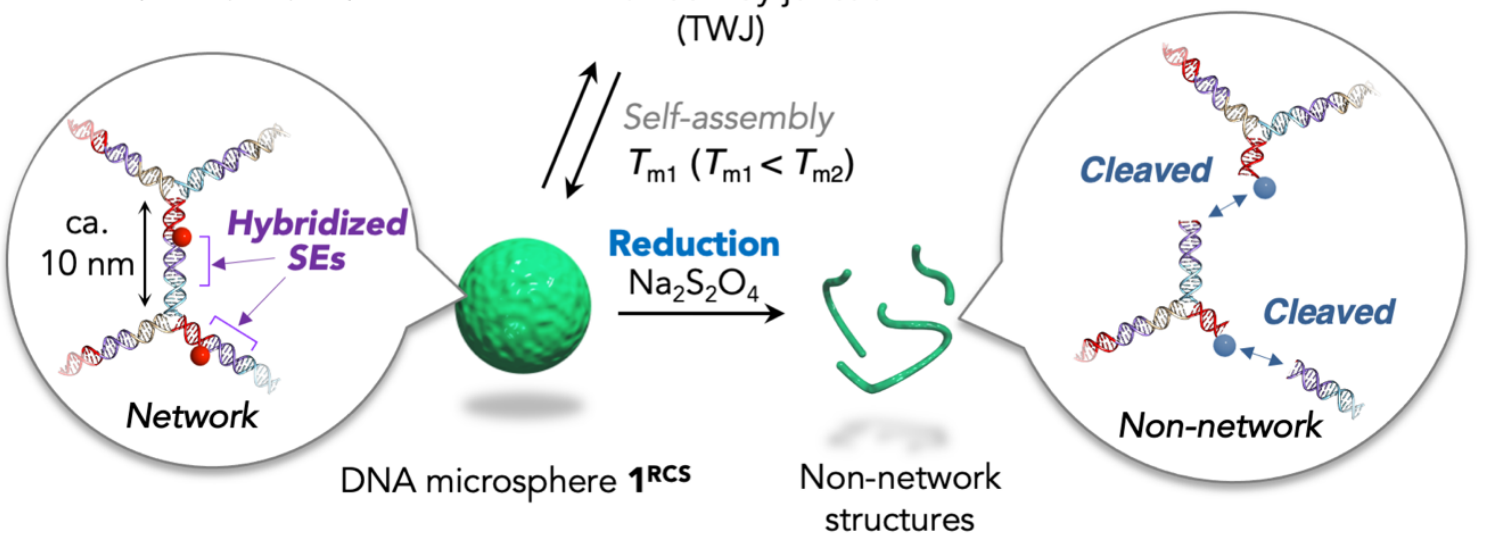

Figure 2 (A) DNA sequences used in this study. (B) Schematic showing the formation of DNA microsphere $\mathbf{1}^{\mathrm{RCS}}$ from three ssDNAs $\left(\mathbf{s} \mathbf{1}^{\mathrm{RCS}}+\mathbf{s} \mathbf{2}+\mathbf{s 3}\right)$. Reduction-responsive DNA microsphere using a reductioncleavable spacer of nitrobenzene scaffold.

Solid phase synthesis and purification of ssDNA $\mathbf{s} 1^{\text {RCS }}$ were performed according to the standard procedure described in the supporting information (Figure S1). To investigate the formation of microspheres from the two pairs of three ssDNAs ("s1 + s2 + s3" for DNA microsphere $\mathbf{1}$ and "s1 $\mathbf{1}$ RCs $+\mathbf{s} \mathbf{2}+\mathbf{s 3}$ " for DNA microsphere $\mathbf{1}^{\mathbf{R C S}}$ ), CLSM observations were performed using a fluorescent dye (i.e., EvaGreen) to visualize the morphologies [17]. First, we investigated the effect of the concentrations of ssDNA (i.e., 2.5 and $10 \mu \mathrm{M}$ ) and $\mathrm{Mg}^{2+}(12.5$ and $25 \mathrm{mM})$ on the microsphere formation ability. As shown in Figure 3A_ii, for DNA 
microsphere $\mathbf{1}^{\mathrm{RCS}}$, particulate morphology was observed at high ssDNA of $10 \mu \mathrm{M}$ when $\mathrm{Mg}^{2+}$ concentration

68 is $25 \mathrm{mM}$, whereas not-well defined structures were found at low $\mathrm{Mg}^{2+}$ concentration of $12.5 \mathrm{mM}$ even at the

69 higher ssDNA concentration of $10 \mu \mathrm{M}$ (Figure 3A_i). On the contrary, for the DNA microsphere 1 (Figure

70 3B), similar particulate morphology was observed at low ssDNA and $\mathrm{Mg}^{2+}$ concentrations $(2.5 \mu \mathrm{M}$ and 12.5

$71 \mathrm{mM}$, respectively), which is consistent with a previous report [14]. Moreover, as shown in Figure 3C, the

72 DNA microsphere $\mathbf{1}^{\text {RCS }}$ exhibited a lower circularity than the DNA microsphere $\mathbf{1}$. The average sizes of the

73 DNA microspheres $\mathbf{1}$ and $\mathbf{1}^{\mathrm{RCS}}$ estimated from CLSM images under the same conditions were $1.61 \pm 0.47$

74 and $1.68 \pm 0.64 \mu \mathrm{m}$, respectively (Figure 3D). The observed differences in the morphology as well as

75 formation ability between the DNA microspheres $\mathbf{1}$ and $\mathbf{1}^{\mathbf{R C S}}$ would be ascribed to flexibility and extra length

76 of RCS introduced between the TWJ core and the SE, which could attenuate efficient formation of networked

77 structures suitable for microsphere formation. Although the formation of smaller self-assembled structures

78 (i.e., $<1 \mu \mathrm{m}$ ) in the solutions containing "s1 $\mathbf{1}^{\mathbf{R C S}}+\mathbf{s} \mathbf{2}+\mathbf{s 3}$ " might be expected [14a], we focused on DNA

79 microspheres $\mathbf{1}$ and $\mathbf{1}^{\text {RCS }}$ in the following study.

80 

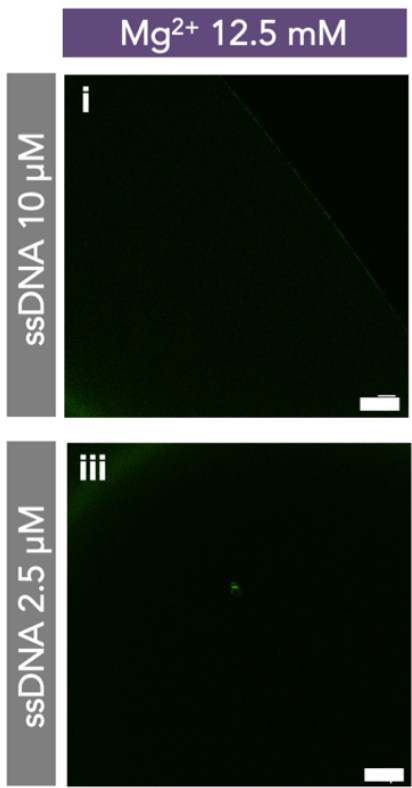

C

DNA microsphere $1^{\text {RCS }}$

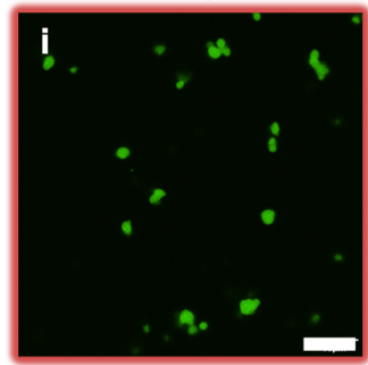

DNA microsphere 1

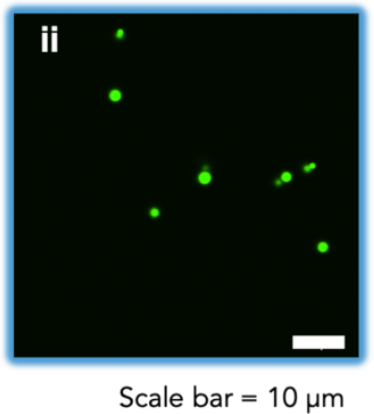

\section{$\mathrm{Mg}^{2+} 12.5 \mathrm{mM}$}
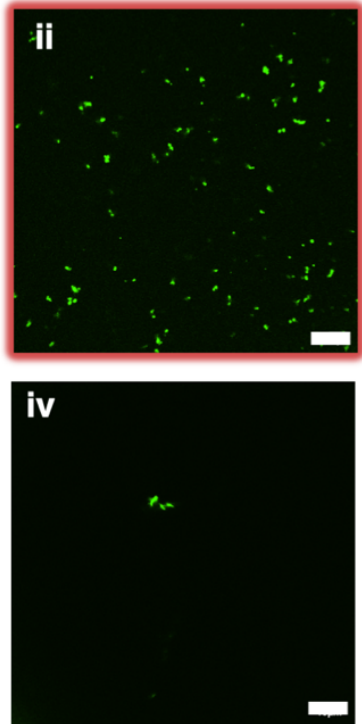

Scale bar $=10 \mu \mathrm{m}$
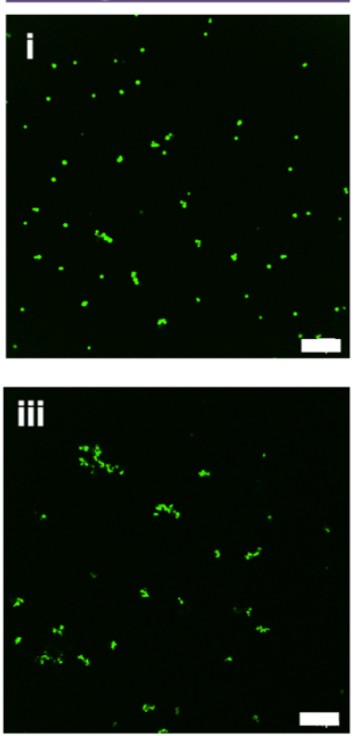

D
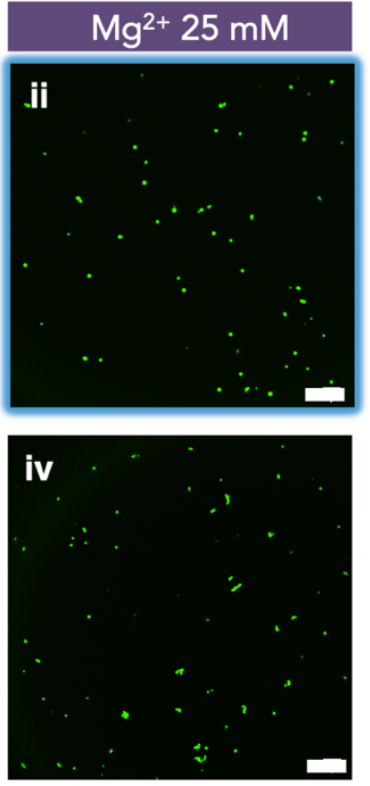

Scale bar $=20 \mu \mathrm{m}$

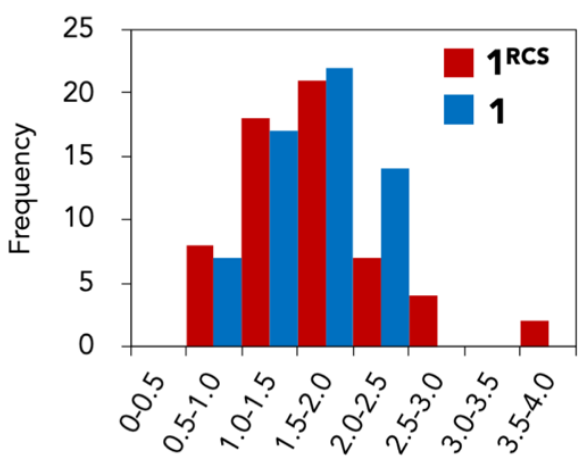

Size $(\mu \mathrm{m})$

Figure 3 Representative CLSM images of (A) DNA microspheres $\mathbf{1}^{\mathbf{R C S}}$ consisting of ssDNAs "s1 $\mathbf{1}^{\mathbf{R C S}}+\mathbf{s} \mathbf{2}+$ $\mathbf{s 3}$ " and (B) DNA microspheres 1 consisting of "s1 + s2 + s3" prepared under different conditions. Magnified images of $\mathbf{A} \_$ii and $\mathbf{B}$ _ii are shown in panel (C). (D) Histogram analysis of the size of DNA microspheres $\mathbf{1}^{\mathrm{RCS}}$ and 1 prepared at $10 \mu \mathrm{M}$ ssDNA in the presence of $25 \mathrm{mM} \mathrm{Mg}(\mathrm{OAc})_{2}$. Conditions: Solution A:B = 5:1 $(v / v)$; Solution A: [DNA $\left(\mathbf{s 1}\right.$ or $\left.\left.\mathbf{s 1}{ }^{\text {RCS }}, \mathbf{s 2}, \mathbf{s 3}\right)\right]=2.5$ or $10 \mu \mathrm{M}$ in an aqueous buffer $(10 \mathrm{mM}$ Tris-acetate $(\mathrm{pH}$ 8.3) containing 12.5 or $25 \mathrm{mM} \mathrm{Mg}(\mathrm{OAc})_{2}$ and $1.0 \mathrm{mM}$ EDTA), Solution B: [EvaGreen] $=25 \mu \mathrm{M}$ in an aqueous buffer (10 mM Tris-acetate (pH 8.3) containing 1.0 mM EDTA), CLSM observations were conducted at ambient temperature.

With the DNA microspheres $\mathbf{1}^{\mathbf{R C S}}$ were in hand, their stimuli-responsiveness was next investigated. First, the reduction-responsive cleavage of $\mathbf{s} 1^{\mathrm{RCS}}$ in the single-stranded state was evaluated using polyacrylamide gel electrophoresis (PAGE). A decrease in the band intensity of $\mathbf{s} 1^{\text {RCs }}$ (lane 4-9) was observed with a concurrent increase in that of the cleaved product, as shown in Figure 4A. This depends on the concentration of the chemical reducing agent used (i.e., $\mathrm{Na}_{2} \mathrm{~S}_{2} \mathrm{O}_{4}$ ). Further, the cleaved product showed 
band shift comparable to that observed in $\mathbf{s} \mathbf{1}^{\text {W/O SE }}$ (lane 1); thus, it can be assigned to $\mathbf{s} \mathbf{1}^{\mathbf{F}}$. The band assignable to a shorter fragment pSE (10 nt) was not found under the conditions. Nevertheless, we disclosed that the significant amount (approximately 85\%) of $\mathbf{s} 1^{\text {RCS }}$ was consumed after the addition of $20 \mathrm{mM} \mathrm{Na} \mathrm{S}_{2} \mathrm{O}_{4}$ as the final concentration (lane 8, Figure 4B). We then performed CLSM observations to evaluate the reductionresponsiveness of the DNA microsphere $\mathbf{1}^{\text {RCS }}$. The obtained results revealed that the particulate morphology disappeared within $1 \mathrm{~min}$ after the addition of the aqueous $\mathrm{Na}_{2} \mathrm{~S}_{2} \mathrm{O}_{4}(28 \mathrm{mM}$ as the final concentration, which is expected to be enough from Figure 4B), as shown in Figure 5A_ii. This indicated the reduction-responsive degradation/disassembly of the DNA microsphere $\mathbf{1}^{\text {RCS }}$. Further, PAGE analysis revealed the formation of the cleaved product under the given conditions for the reduction-responsive disassembly of DNA microsphere $\mathbf{1}^{\mathrm{RCS}}$ (lane 7, Figure 4C). In contrast, after adding nonreducing agent $\mathrm{Na}_{2} \mathrm{SO}_{4}(28 \mathrm{mM}$ as the final concentration), a certain extent of aggregation possibly due to the increased salt concentration was observed but disassembly was not induced (Figure 5A_iv). Moreover, reduced glutathione (5 $\mathrm{mM}$ as the final concentration, which is comparable with its intracellular concentration) did not significantly change the morphology (Figure 5A_v). These results indicate that the selective disassembly of the DNA microsphere $\mathbf{1}^{\text {RCS }}$ in response to $\mathrm{Na}_{2} \mathrm{~S}_{2} \mathrm{O}_{4}$ was triggered by the reduction of the nitrobenzene scaffold in $\mathbf{s} 1^{\mathbf{R C S}}$ and the subsequent cleavage reaction via $\beta$-1,6-elimination, as depicted in Figure 2A. In contrast, DNA microsphere $\mathbf{1}$ showed no degradation/disassembly response, while a certain extent of aggregation, toward the chemical reducing agent $\mathrm{Na}_{2} \mathrm{~S}_{2} \mathrm{O}_{4}(28 \mathrm{mM}$ as the final concentration) under the same conditions as for the DNA microsphere $\mathbf{1}^{\text {RCS }}$ (Figure 5B_ii). Finally, the DNA microspheres $\mathbf{1}^{\text {RCS }}$ and $\mathbf{1}$ showed endonuclease DNase Iresponsive degradations, as shown in Figure 5A_iii and $\mathbf{5 B}$ _iii, respectively, which is reasonable and consistent with previous reports [14,17]. 
A

$$
\begin{array}{r}
\text { ssDNA s1w/ose + } \\
\text { ssDNA s1 } \\
\text { ssDNA s1 }{ }^{R C s}
\end{array}
$$

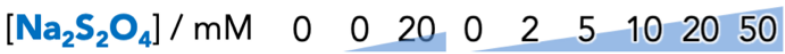

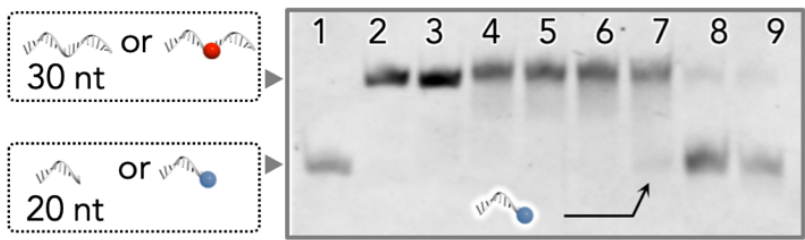

\section{C

$$
\text { SSDNA s1RCS }++
$$$$
\text { SSDNA s1w/ose + }
$$

DNA microsphere 1

DNA microsphere $\mathbf{1}^{\text {RCS }}$

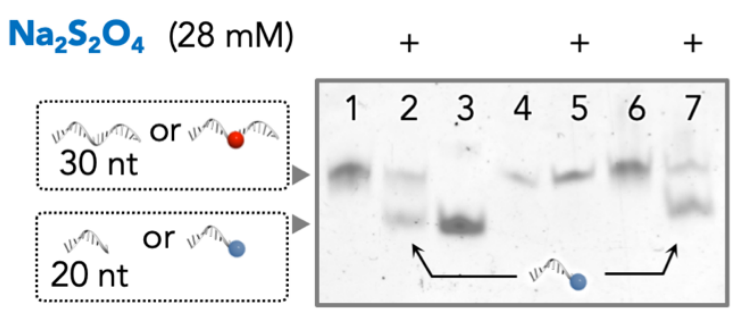

B

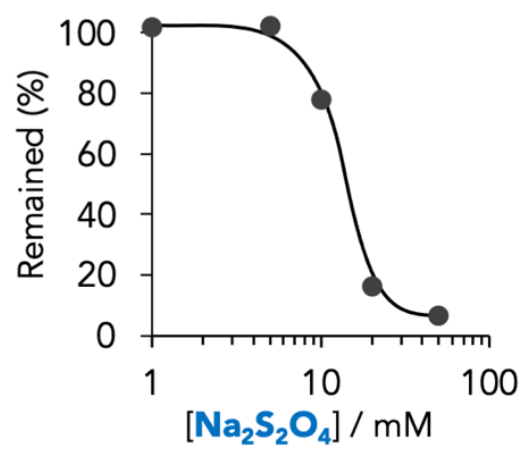

Figure 4 (A) PAGE (20\%, denatured, SYBR Green II) analysis to evaluate reduction-responsive cleavage of ssDNA s1 ${ }^{\text {RCS }}$ and $\mathrm{Na}_{2} \mathrm{~S}_{2} \mathrm{O}_{4}$ dependence of remained $\mathbf{s 1}^{\text {RCS }}(\%)$ (B). (C) PAGE (20\%, denatured, SYBR Green II) analysis to evaluate reduction-responsive cleavage of DNA microsphere $\mathbf{1}^{\text {RCS }}$. Conditions: Solution A:B $=5: 1(v / v)$, Solution A: [DNA (s1 or $\left.\left.\mathbf{s 1}{ }^{\mathrm{RCS}}, \mathbf{s 2}, \mathbf{s 3}\right)\right]=10 \mu \mathrm{M}$ in an aqueous buffer $(10 \mathrm{mM}$ Tris-acetate $(\mathrm{pH}$ 8.3) containing $25 \mathrm{mM} \mathrm{Mg}(\mathrm{OAc})_{2}$ and $1.0 \mathrm{mM}$ EDTA), Solution $\mathrm{B}:\left[\mathrm{Na}_{2} \mathrm{~S}_{2} \mathrm{O}_{4}\right.$ or $\left.\mathrm{Na}_{2} \mathrm{SO}_{4}\right]=0 \sim 300 \mathrm{mM}$ in an aqueous buffer (10 mM Tris-acetate (pH 8.3) containing $25 \mathrm{mM} \mathrm{Mg}(\mathrm{OAc})_{2}$ and $1.0 \mathrm{mM}$ EDTA), ambient temperature. 
A DNA microsphere $\mathbf{1}^{\text {RCS }}$

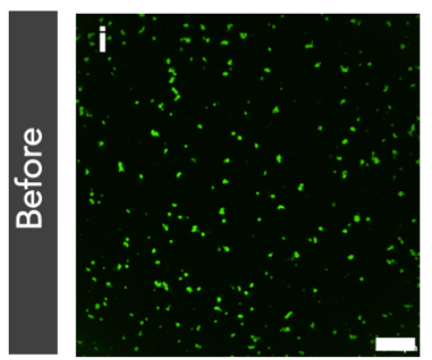

vi

\begin{tabular}{|c|c|}
\hline $\begin{array}{c}\mathrm{Na}_{2} \mathrm{~S}_{2} \mathrm{O}_{4} \\
+\end{array}$ & $\begin{array}{c}\text { DNase I } \\
+\end{array}$ \\
\hline $\mathrm{Na}_{2} \mathrm{SO}_{4}$ & $\mathrm{GSH}$ \\
- & - \\
\hline
\end{tabular}

B DNA microsphere 1

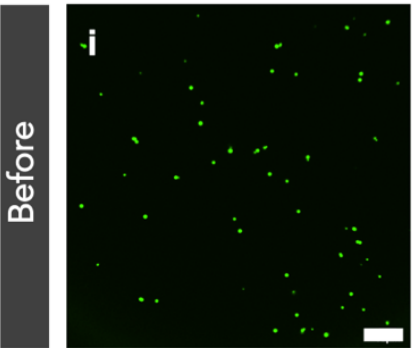

vi

\begin{tabular}{|c|c|}
\hline $\begin{array}{c}\mathrm{Na}_{2} \mathrm{~S}_{2} \mathrm{O}_{4} \\
-\end{array}$ & DNase I \\
\hline $\mathrm{Na}_{2} \mathrm{SO}_{4}$ & GSH \\
- & - \\
\hline
\end{tabular}

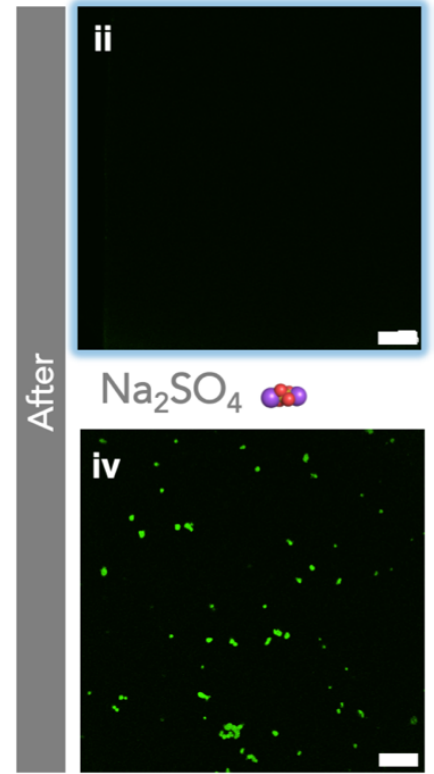

$\mathrm{Na}_{2} \mathrm{~S}_{2} \mathrm{O}_{4}$
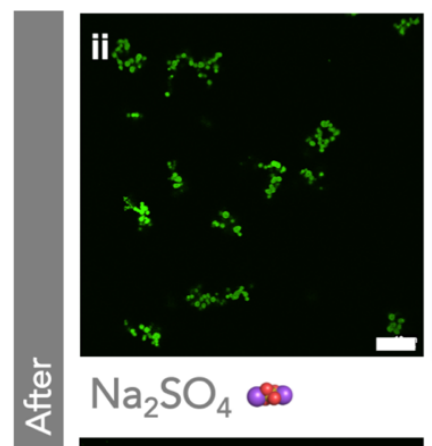

$\mathrm{Na}_{2} \mathrm{SO}_{4}$
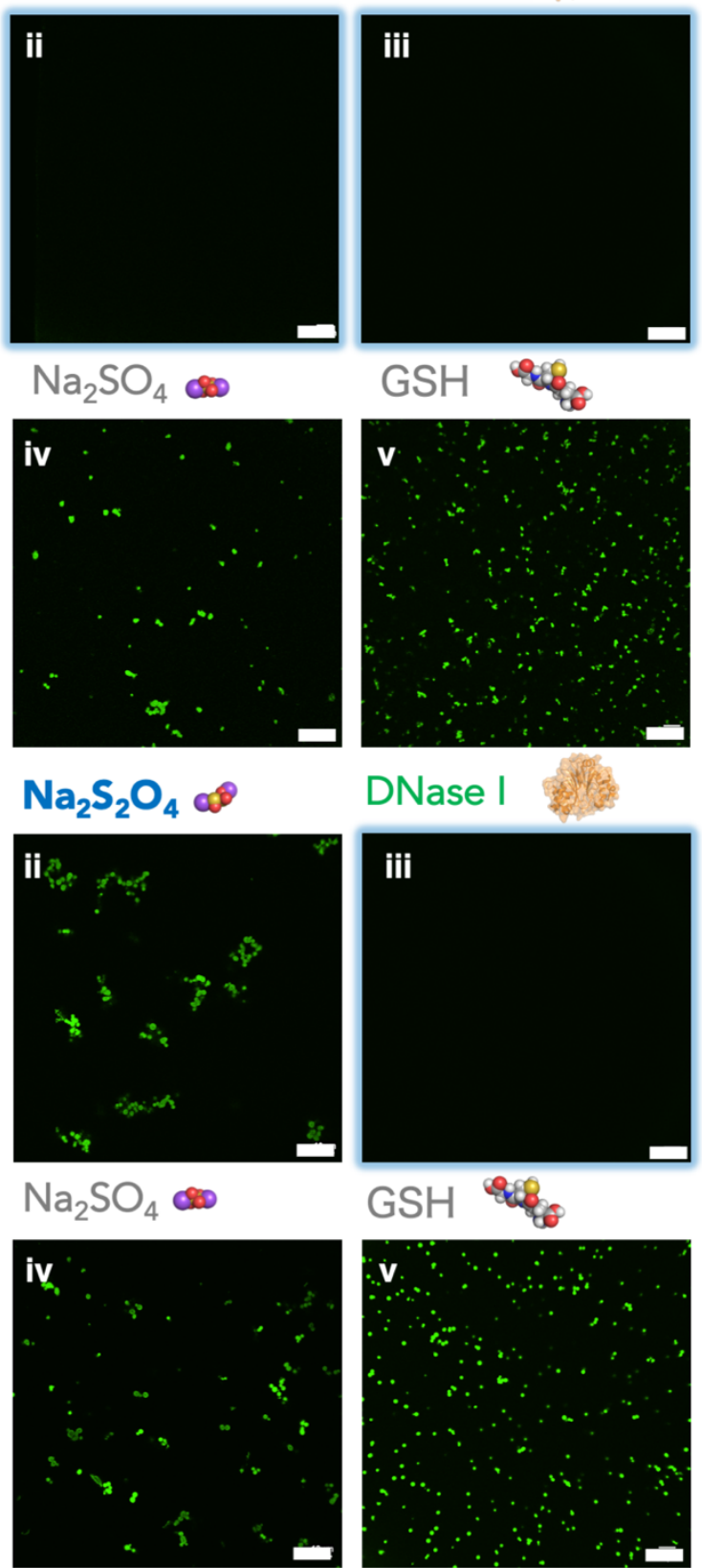

DNase I

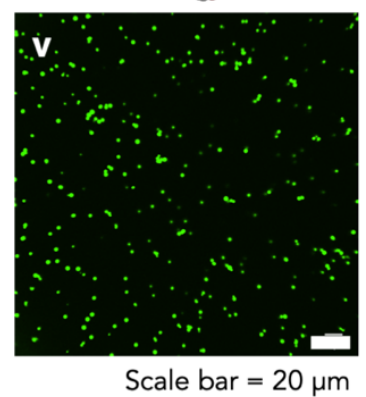

Figure 5 Stimuli responsiveness of DNA microspheres (A) $\mathbf{1}^{\text {RCS }}$ and (B) $\mathbf{1}$. Representative CLSM images of DNA microsphere $\mathbf{1}^{\mathrm{RCS}}$ and $\mathbf{1}$ (i) before and after the addition of stimuli (ii: $\mathrm{Na}_{2} \mathrm{~S}_{2} \mathrm{O}_{4}$ (after $1 \mathrm{~min}$ ), iii: DNase I (after $15 \mathrm{~min}$ ), iv: $\mathrm{Na}_{2} \mathrm{SO}_{4}$ (after $\left.1 \mathrm{~min}\right)$, v: GSH (after $\left.1 \mathrm{~min}\right)$ ). Stimuli responsiveness (+,-) of each DNA microsphere is summarized in panel (vi). Conditions: Solution A:B:C $=5: 1: 1(v / v / v)$, Solution A: [DNA (s1 or $\left.\left.\mathbf{s 1}{ }^{\text {RCS }}, \mathbf{s 2}, \mathbf{s 3}\right)\right]=10 \mu \mathrm{M}$ in an aqueous buffer $\left(10 \mathrm{mM}\right.$ Tris-acetate $(\mathrm{pH} 8.3)$ containing $25 \mathrm{mM} \mathrm{Mg}(\mathrm{OAc})_{2}$ and $1.0 \mathrm{mM}$ EDTA), Solution B: [EvaGreen] $=25 \mu \mathrm{M}$ in an aqueous buffer $(10 \mathrm{mM}$ Tris-acetate $(\mathrm{pH} 8.3)$ containing $1.0 \mathrm{mM}$ EDTA), Solution C: $\left[\mathrm{Na}_{2} \mathrm{~S}_{2} \mathrm{O}_{4}\right.$ or $\left.\mathrm{Na}_{2} \mathrm{SO}_{4}\right]=200 \mathrm{mM}$ or $\left[\mathrm{Na}_{2} \mathrm{~S}_{2} \mathrm{O}_{4}\right.$ or $\left.\mathrm{Na}_{2} \mathrm{SO}_{4}\right] /[\mathrm{DNA} \mathbf{s 1}$ or $\left.\mathbf{s 1}^{\mathrm{RCS}}\right]=$ approx. 4,000$)$ or $[\mathrm{GSH}]=35 \mathrm{mM}$ in an aqueous buffer $(10 \mathrm{mM}$ Tris-acetate $(\mathrm{pH} 8.3)$ containing $1.0 \mathrm{mM}$ EDTA) or $[$ DNase $\mathrm{I}]=0.1 \mathrm{U} / \mu \mathrm{L}$, ambient temperature.

\section{Conclusion}

In summary, we demonstrated that the RCS containing a nitrobenzene scaffold can be incorporated 
into the ssDNA sequence to enable the construction of a reduction-responsive DNA architecture with spherical morphology at micrometer scale. Since the preparation of RCS-based phosphoramidite reagent for the construction of oligonucleotides containing RCS is straightforward, the RCS could allow for the introduction of the reduction-responsiveness into various functional oligonucleotides and nucleic acid-based architectures toward therapeutic and diagnostic applications.

\section{Acknowledgments}

This work was supported in part by financial supports from the Uehara Memorial Foundation, the JSPS Core-to-Core Program, iGCORE collaboration grant (MI), a Grant-in-Aid for Scientific Research (C) of the Japan Society for the Promotion of Science (20K05563, AS), and JSPS Research Fellowship for Young Scientists (SLH). We acknowledge Life Science Research Center, Gifu University for their kind and continuous support. The authors would like to thank Enago (www.enago.jp) for the English language review.

\section{Conflict of Interest}

The authors declare no conflict of interest.

Keywords: Self-assembly $\bullet$ DNA structures $\bullet$ Cleavage reaction $\bullet$ Reduction

\section{References}

[1] a) D. Bhatia, C. Wunder, L. Johannes, ChemBioChem 2021, 22, 763-778; b) X. Wang, A. R. Chandrasekaran, Z. Shen, Y. P. Ohayon, T. Wang, M. E. Kizer, R. Sha, C. Mao, H. Yan, X. Zhang, S. Liao, B. Ding, B. Chakraborty, N. Jonoska, D. Niu, H. Gu, J. Chao, X. Gao, Y. Li, T. Ciengshin, N. C. Seeman, Chem. Rev. 2019, 119, 6273-6289; c) J. Wang, D. X. Wang, B. Liu, X. Jing, D. Y. Chen, A. N. Tang, Y. X. Cui, D. M. Kong, Chem. Asian J. 2022, in press, doi: 10.1002/asia.202101315.

[2] a) M. Xiao, W. Lai, T. Man, B. Chang, L. Li, A. R. Chandrasekaran, H. Pei, Chem. Rev. 2019, 119, 1163111717; b) A. Shibata, S. L. Higashi, M. Ikeda, Polym. J. 2022, in press, doi: 10.1038/s41428-022-006231.

[3] A. Keller, V. Linko, Angew. Chem. Int. Ed. 2020, 59, 15818-15833.

[4] S. Nummelin, B. Shen, P. Piskunen, Q. Liu, M. A. Kostiainen, V. Linko, ACS Synth. Biol. 2020, 9, $1923-$ 1940.

[5] a) X. Tang, J. Zhang, J. Sun, Y. Wang, J. Wu, L. Zhang, Org. Biomol. Chem. 2013, 11, 7814-7824; b) M. Ikeda, M. Kabumoto, Chem. Lett. 2017, 46, 634-640; c) H. Saneyoshi, A. Ono Chem. Pharm. Bull. 2018, 66, 147-154; d) Y. Wu, Z. Yang, Y. Lu, Curr. Opin. Chem. Biol. 2020, 50, 95-104; e) L. Yang, I. J. Dmochowski, Molecules 2021, 26, 1481; f) S. Mori, K. Morihiro, T. Okuda, Y. Kasahara, S. Obika, Chem. Sci. 2018, 9 , 
1112-1118; g) L. Xiao, C. Gu, Y. Xiang, Angew. Chem. Int. Ed. 2019, 58, 14167-14172.

[6] a) M. Ikeda, M. Kamimura, Y. Hayakawa, A. Shibata,Y. Kitade, ChemBioChem 2016, 17, 1304-1307; b) Y. Hayakawa, A. Banno, H. Kitagawa, S. Higashi, Y. Kitade, A. Shibata, M. Ikeda, ACS Omega 2018, 3, 92679275.

[7] A. Banno, S. Higashi, A. Shibata, M. Ikeda, Chem. Commun. 2019, 55, 1959-1962.

[8] N. Shirakami, S. L. Higashi, Y. Kawaki, Y. Kitamura, A. Shibata, M. Ikeda, Polym. J. 2021, 53, 741746.

[9] N. Shirakami, Y. Kawaki, S. L. Higashi, A. Shibata, Y. Kitamura, S. Abu Hanifah, L. Lee Wah, M. Ikeda, Chem. Lett. 2021, 50, 1412-1415.

[10] a) Dick Yan Tam, Xinyu Zhuang, Sze Wing Wong, Pik Kwan Lo, Small 2019, 15, 1805481; b) R. E. Kohman, X. Han, Chem. Commun. 2015, 51, 5747-5750.

[11] R. E. Kohman, S. S. Cha, H.-Y. Man, X. Han, Nano Lett. 2016, 16, 2781-2785.

[12] F. Huang, W.-C. Liao, Y. Sung Sohn, R. Nechushtai, C.-H. Lu, I. Willner, J. Am. Chem. Soc. 2016, 138, 8936-8945.

[13] C. Jin, A. H. EI-Sagheer, S. Li, K. A. Vallis, W. Tan, T. Brown, Angew. Chem. Int. Ed. 2022, in press, doi: 10.1002/anie.202114016.

[14] a) K. Matsuura, T. Yamashita, Y. Igami, N. Kimizuka, Chem. Commun. 2003, 376-377; b) K. Matsuura, K. Masumoto, Y. Igami, T. Fujioka, N. Kimizuka, Biomacromolecules 2007, 8, 2726-2732; c) Y. Kamiya, Y. Yamada, T. Muro, K. Matsuura, H. Asanuma, ChemMedChem 2017, 12, 2016-2021; d) H. Inaba, K. Hatta, K. Matsuura, ACS Appl. Bio Mater. 2021, 4, 5425-5434.

[15] M. Ikeda, T. Tanida, T. Yoshii, K. Kurotani, S. Onogi, K. Urayama, I. Hamachi, Nat. Chem. 2014, 6, 511-518.

[16] A. V. Sharrock, T. S. Mulligan, K. R. Hall, E. M. Williams, D. T. White, L. Zhang, K. Emmerich, F. Matthews, S. Nimmagadda, S. Washington, K. D. Le, D. Meir-Levi, O. L. Cox, M. T. Saxena, A. L. Calof, M. E. LopezBurks, A. D. Lander, D. Ding, H. Ji, D. F. Ackerley, J. S. Mumm, Nat. Methods 2022, 19, 205-215.

[17] a) S. L. Higashi, A. Shibata, Y. Kitamura, K. M. Hirosawa, K. G.N. Suzuki, K. Matsuura, M. Ikeda, Chem. Eur. J. 2019, 25, 11955-11962; b) S. L. Higashi, K. M. Hirosawa, K. G.N. Suzuki, K. Matsuura, M. Ikeda, ACS Appl. Bio Mater. 2020, 3, 9082-9092. 